\title{
Heuristic-Based Algorithm for Production Planning Considering Allocation Rate Conformance to Prevent Unstable Production Chain
}

\author{
Taehun Kim, Bongjun Ji, Hyunbo Cho* \\ Department of Industrial and Management Engineering, Pohang University of Science and Technology, \\ Pohang, Korea
}

(Received: December 14, 2015 / Revised: December 19, 2015 / Accepted: December 20, 2015)

\begin{abstract}
This study solved the problem of unstable production chains by considering allocation rate conformance. We proposed two phased algorithm suitable for solving production planning that considers allocation rate conformance; the first phase was heuristic initial solution generation, and the second phase was tabu-search based solution improvement. By using three data sets which have different sizes of data and three different criteria, the results of proposed algorithm were compared with MIP results. The proposed algorithm showed the best production plan in terms of allocation rate conformance, and it was appropriate for other criteria; it solved the problem of unstable production chains by solving concentrated and unfair allocation.
\end{abstract}

Keywords: Tabu Search, Imbalanced Allocation, Unfair Allocation, Production Contract

* Corresponding Author, E-mail: hcho@postech.ac.kr

\section{INTRODUCTION}

Production planning is a core competency of global manufacturers. It determines how many items should be produced in each time over a given interval to meet the demands. Specifically, production planning can be classified according to several criteria such as product structure, uncertainty management and material requirement management (Gelders and Wassenhove, 1981). Production planning can be classified according to product structure into single-level production planning or multilevel production planning. Single-level production planning only considers the costs and capacities of each site's production level, whereas multi-level production planning should also consider transportation among production levels (Chen, 2010). According to uncertainty management, production planning can be classified as deterministic production planning or stochastic production planning. Deterministic production planning assumes that the forecast demands, material procurements and the lead-time of item production and delivery are determined, whereas the stochastic production planning considers these variables to be uncertain. According to material requirement management, production planning can be classified as material requirement planning or material allocation planning. Material requirement planning assumes that all materials are available and calculates the required amount of each material according to the production plan, whereas material allocation planning must make plans that use only materials that are available or will be available soon.

In this work, we consider multi-level, deterministic, 
material allocation production planning. Several approaches have been suggested to solve this type of production planning (Roux et al., 1999; Timpe and Kallrath, 2000; Moon, 2002; Vercellis, 1999). The main idea of solving production planning is to minimize cost. This goal was approached using mathematical models and mixedinteger programming (MIP), but the cost-driven optimization had two limitations: concentrated allocation to sites that had low production cost, and violation of production chain coordination contracts. Concentrated allocation causes an unstable production chain because the chain become rigid when an external or internal accident forces changes to the allocation plan (Wagner and Bode, 2006). Moreover, concentrated allocation to small manufacturing sites that have small capacity requires overwork, and thus causes inefficiency and increase of costs. Cost-driven optimization violates contracts easily because it is not suitable to consider the contract constraints (Cachon, 2003). We needed to eliminate both unfair and concentrated allocations that violate production chain coordination contracts and cause unstable production chain.

By introducing allocation rate, we could meet both of these requirements. We assumed a multi-level, deterministic, material allocation production planning, so our production chain has several production levels. A higherlevel item is produced from lower-level items. Some items have the same features such as appearance, quality, and function, but different item codes (IDs). When the items are isolated by their physical locations of manufacturing site or warehouses, different item codes are assigned. The higher-level item then has alternative lowerlevel items, so we can select one of them. When the higher-level item has non-zero allocation rate for the lower-level items, we should consider each allocation rate. In contrast, when the higher-level item has zero allocation rate for the lower-level items, we can produce without considering the allocation rate. Appropriate allocation rate that comply with contracts could prevent unfair and concentrated allocation because the allocation rate will prohibit allocations from exceeding the limits defined by the contracts. Production planning with allocation rate is a multi-objective optimization, so we must evaluate each solution by several criteria such as minimizing total cost, minimizing number of orders that violate due date, and maximizing allocation rate compliance. Multi-objective optimization is a mathematical optimization problem that involves more than one objective function to be optimized simultaneously (Hwang and Masud, 1979). However, the general approach (MIP) is not suitable for multi-objective optimization because solving a multi-objective optimization problem requires computing all or a representative set of Pareto optimal solutions (Ehrgott, 2005). Computing all possible Pareto solutions is very time consuming and entails high computational cost; this general approach is inappropriate for use in a manufacturing domain, so we needed different approach.
We proposed a new algorithm for solving production planning with allocation rate. We used a heuristic algorithm to solve this problem. Our algorithm consists of two parts: initial solution generation algorithm based on simple heuristic rules and solution improvement algorithm based on tabu search (Glover, 1990).

\section{DATA AND ALGORITHM DESCRIPTION}

\subsection{Data Description}

\subsubsection{Data Collection}

The formats of data were constructed based on real data of one past production-planning period from an electronics manufacturer in Korea. The original data are from one past production-planning period of the company. The company needs to solve the subcontract rate problem, and requested help to solve this problem with given data. The original data includes procurement records of raw materials, bills of materials (BOMs) of products, and subcontract rate, but the records of placed orders are not offered; thus we created the virtual order data. We converted these to BOM data, material plan, resource plan, and order data.

\subsubsection{BOMs Data}

BOM data represented the product constitution. BOM data structure was organized in a tree structure, which has parent and child nodes. BOM data consisted of parent nodes (and their IDs), child nodes (and their IDs), required number, alternative ID, and subcontract rate. To produce one parent node item, the required number of child node items is needed. Each parent-child relation has an alternative ID that represents the interchangeable groups. If the child nodes have the same alternative ID, they have equivalent relations with their parent, so they are in the same interchangeable group and the parent node can be assembled from any one of those group members. If the alternative IDs differ between child nodes, those nodes are not interchangeable. For instance, a parent node having three different alternative IDs requires three types of items to be produced such as camera group, battery group and cover group.

An interchangeable group has two types of relationships according to its subcontract rate. If the subcontract ratesare zero for all interchangeable group items, then we can assign them as freely as possible regardless of subcontract rate. If an interchangeable group has only one item, then the item is automatically regarded as this first type. However, if the interchangeable group has non-zero subcontract rate, the sum of those rate should be one and the subcontract rate between interchangeable groups should be fitted to given subcontract rate as much as possible.

\subsubsection{Material and Resource Plan Data}

Material plan data has replenishment numbers of 
raw materials with specific times. Material plan data has information about usability of raw materials in the view point of time and amount. Material plan data has the time when specific raw materials are replenished to factory or warehouse. In addition, material plan data has replenished a number of specific raw materials. In the view of time, raw materials are available after they are stored. In the view of number, raw materials are available as many as they are replenished. Raw materials are required to produce parts, thus if raw material is lacking, the part cannot be produced. The production plan should consider the resource plan.

Resource plan data has usability of each resource (production equipment, labor). Resource plan data also has up/down information of equipment, work time of workers, and the information that how much we can use these resource in the perspective of required time to produce the items.

\subsubsection{Order Data}

Order data has information about the order quantity, order priority and due date of order. Order quantity is equal to the required number of products to meet the customer demand. Order priority is related to customer importance, which means the importance of the customer who placed order. The due date of order is the deadline of production. Usually the due date of an order is considered first, but in this case, order priority should be considered before due date.

\subsection{Proposed Planning Algorithm}

\subsubsection{Assumptions and Problem Situations}

We started from industrial requirements, thus several assumptions are related to the industrial requirements. We assumed that we could not split the order, which means that if the order quantity is 100 , then we should assign all 100 assemblies to one subcontractor. Split order quantity caused low traceability in the production chain, and consequent difficulties in production management. If the order was split, then delivery arrival times of split order quantity were not unified among subcontractors, so extra inventory storage and management were necessary.

We used a heuristic method for three reasons. First, the production planning was required to meet the time constraint. Previous approaches using MIP solvers may have a problem that a solution cannot be generated in limited time. MIP can guarantee the optimality of solution if it is finished, but it cannot guarantee the optimality if it is terminated by the time constraints. In fact production planning solution that required more than four hour is avoided due to planners' work hour limit and low level of plan modification. Second, production planning was required to generate the solution even it is infeasible. If a feasible solution does not exist, the planning algorithm should generate the least infeasible solution, which means that the solution should violate the fewest constraints possible. Usual MIP approaches search around the solution boundaries bounded by the constraints, so these approaches cannot find the least infeasible solution. Third, we need to solve multi-objective production planning problem, however, finding relative importance of key performance indicators (KPIs) is not easy problem, thus we cannot develop proper objective function for MIP. For these reason, we developed the heuristic-based algorithm and it has two phases: development of an initial solution generation by greedy heuristic; then improvement of this solution by using tabu search (Glover, 1990).

\subsubsection{Production Planning Model for Comparison}

Our primal production planning model is based on the multi-site production planning mathematical model (Lin and Chen, 2007). We modified this model by adding the concept to prevent split of order quantities and order priority constraints. In addition, the allocation rate conformance is considered by adding the allocation rate variables.

The objective functions for the production planning model used by MIP are $\operatorname{Maxf}(\mathrm{x})$ if order satisfaction level; Min $\mathrm{f}(\mathrm{x})$ if days of due date violation. Detail descriptions of objective functions are followed.

Order satisfactory level was measured by

$$
\frac{\sum_{i=1}^{n} D_{i}}{\mathrm{n}}
$$

Where $D_{i}=1$ if the order is satisfied (produced before the due date), otherwise $D_{i}=0$.

Days of due date violation was measured by

$$
\sum_{i=1}^{n} \max \left\{0, D D_{i}-P_{i}\right\}
$$

where $D D_{i}=$ due date of order $i, P_{i}=$ production date of order $i$.

Other constraints also considered: Inventory balance equations; item consumption rate equations; resource capacity constraint.

We use two different objective functions instead of the one cost based objective function because relative importance of target variable is heavily dependent of the factory or supply chain situation. The first objective function is order satisfaction level, which means how many customers' orders are satisfied according to the due date of orders. Second objective function is days of due date violation, which means total sum of number of days which violate due date. According to the order satisfaction level, we can consider the plan which did not allow late (or backordering) production, and according to the days of due date violation, we can consider the plan allowing late production. The allocation rate conformance would not considered in the MIP to be compared with our proposed algorithm. 


\subsubsection{Initial Solution Generation Algorithm}

Initial solution generation was based on a greedy heuristic algorithm. The order data were sorted first by the highest order priority, then by the closest due date and then by the largest order quantity. For each order having the highest priority, we calculated the amount of consumable raw materials according to raw material consumption and replenishment data. This calculation finds the maximum consumable raw materials for every interchangeable group, and selects the maximum consumable raw materials of each interchangeable group. For the maximum consumable raw materials of each interchangeable group, we could calculate the recent allocation rate within an interchangeable group as

$$
\begin{aligned}
& (\text { recent allocation rate })_{i}= \\
& (\text { alternative rate })_{i}-\frac{\text { planned quantity }}{\text { total planned quantity }}
\end{aligned}
$$

where $i$ is an index of items in interchangeable group.

Next, we assigned the order quantity to the item that had the highest recent allocation rate. If no assignment was possible, i.e., the maximum amounts of raw materials were less than the ordered quantity, we shifted the time. If the shifted time reached the end of the planning horizon, we repeated this process for all levels of order priority in descending order. These are the steps to generate the initial solution:

Step 1: Sort the order data by the highest order priority, the closest due date, the largest order quantity.

Step 2: Select the first order and select the raw materials which have maximum consumable number for every interchangeable group.

Step 3: Check whether the maximum consumable number of raw material is greater than or equal to the order quantity, if it is true, go to step 4, else go to step 5 .

Step 4: Calculate recent allocation rate and assign the order quantity to maximum recent allocation rate items for every interchangeable group.

Step 5: Shift the time; if it reaches the end of the planning horizon, remove the order from the sorted order list and reset the position of time to the beginning of the planning horizon.

Step 6: If the sorted order list is null, then end the algorithm, else go to step 2.

\subsubsection{Solution Improvement Algorithm}

From the initial solution, the solution can be improved by using meta-heuristic. Our meta-heuristic algorithm was based on tabu search algorithm (Glover, 1990). Tabu search was basically a neighborhood search to iteratively move from one solution to an improved neighborhood solution. Compared with usual neighborhood search algorithms, tabu search has tabu list which guides the search of unvisited solution space by prohibiting search- ing of neighborhood solution in tabu list. Naturally, neighborhood search has a limitation called local optimum, which means that the search becomes stuck in a limited solution space because of repeated identical neighborhood selections, however, tabu search prohibited visiting the solution space in tabu list for a while. Thus the possibility of exiting the local optimum was dramatically increased.

According to BOM structure and the product relationships, we can define the production path as a sequence of production nodes. Each production node includespro duction quantity, material usage, resource usage, production site. Production path is a sequence of production nodes, in other word, it is a kind of sub-graph of BOM structure. Several kinds of production paths are illustrated in Figure 1 below. A sequence 1-2 and 3-2 could be production paths for product $\mathrm{A}$, and also the resource could be selected between resource ' $a$ ' and ' $b$ '. For example, to produce product $\mathrm{A}$, we should select one of two sequences 1-2 or 3-2, and after that we should select the resource used to produce the items. For example, to produce product $\mathrm{A}$, we can choose production paths among those combinations $\{1 . \mathrm{a}-2 . \mathrm{e} ; 1 . \mathrm{b}-2 . \mathrm{e}$; 1.a-2.f; 1.b-2.f; 3.a-2.e; 3.b-2.e; 3.a-2.f; 3.b-2.f\}.

After selecting production path, the availability is checked. Availability represents the production is available regarding capacity of resource and remain inventory in planning period. If the capacity or inventory is short for selected production quantity of production path, the production path is said unavailable. Checking the availability of production path follows selecting production path, and if the production path is available, it is registered as candidates for tabu search.

We define operation as allocation and release. One allocation operation selects an available production path, and one release operation discard a selected available production path. Either allocation or release are operated, exact same operation in the perspective of production path will be registered in tabu list and will be prohibited

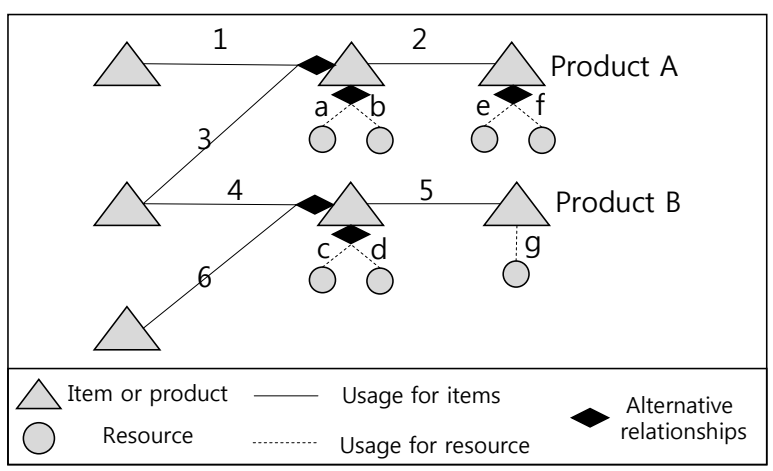

Figure 1. Production BOM structure and production paths. $\Delta$ : items or product; $\bigcirc$ : resource; $\longrightarrow$ : usage (consumption) relationship of items to produce target item; - - -: usage (work assigned) relationship of resource 
for after several operations. This step will be repeated for generate plan.

\section{RESULTS}

\subsection{Result Description}

We compared MIP with proposed algorithm in various perspectives such as order satisfactory level, days of due date violation, and allocation rate conformance.

The MIP approach would not stop before the optimal solution was found, so we set the time limit to four hours (4h). The proposed algorithm could generate different solutions according to their random seeds of tabu selection. Thus, we repeated the experiment 50 times to get the average of each criterion.

Allocation rate conformance was measured by

$$
\sum_{j=1}^{m} \sum_{i=1}^{n_{j}}\left|C R_{i j}-A R_{i j}\right|^{2}
$$

where $C R_{i j}=$ contract rate of $i$-th site in $j$-th interchangeable group, $A R_{i j}=$ allocation rate of $i$-th site in $j$-th interchangeable group.

The experiments were performed with three data sets. The first one was the simplest set, which consisted of 100 orders, ten raw material sites, one manufacturing site and two alternate groups. The second one consisted of 1,000 orders, 50 raw material sites, two manufacturing sites, and ten alternate groups. The third set was the most complicated one, which consisted of 10,000 orders, 100 raw material sites, two manufacturing sites, and 20 alternate groups.

\subsection{Small Size Data Set Result}

With a small size data set, both approaches showed $100 \%$ order satisfactory level, similar level of days of due date violation, and insignificant difference between allocation rate conformances (Table 1).

\subsection{Medium Size Data Set Result}

With a medium size data set, MIP showed the highest order satisfactory level and the shortest days of due date violation compared with proposed algorithm. However, proposed algorithm showed statistically insignificant difference between optimal order satisfactory level ( $\mathrm{p}$-value $=0.3174)$, and offered outstanding allocation rate conformance (Table 2 ).

\subsection{Large Size Data Set Result}

With a large size data set, MIP failed to find the optimal solution in four hours, so it just offered the cur-
Table 1. Mean and s.d. ( $\mathrm{n}=50$ for proposed algorithm) of order satisfactory level, days of due date violation, and allocation rate conformance using MIP and proposed algorithm with 100 orders, ten raw material sites, one manufacturing site, and two alternate groups

\begin{tabular}{ccccc}
\hline & \multicolumn{2}{c}{$\begin{array}{c}\text { Order Satisfaction } \\
\text { Level }\end{array}$} & \multicolumn{2}{c}{$\begin{array}{c}\text { Days of Due Date } \\
\text { Violation }\end{array}$} \\
\hline \multirow{2}{*}{ MIP } & mean & st.dev & mean & st.dev \\
\cline { 2 - 5 } & $\begin{array}{c}100.0 \\
(\mathrm{Opt})\end{array}$ & - & $\begin{array}{c}2.0 \\
(\mathrm{Opt})\end{array}$ & - \\
\hline Proposed & 100.0 & 0.0 & 2.0 & 0.0 \\
\hline $\begin{array}{c}\text { Allocation Confor- } \\
\text { mance for MIP }\end{array}$ & 0.57 & - & 0.62 & - \\
\hline $\begin{array}{c}\text { Allocation Confor- } \\
\text { mance for Proposed }\end{array}$ & 0.39 & 0.26 & 0.39 & 0.26 \\
\hline
\end{tabular}

Table 2. Mean and s.d. ( $\mathrm{n}=50$ for proposed algorithm) of order satisfactory level, days of due date violation, and allocation rate conformance using MIP and proposed algorithm with 1,000 orders, 50 raw material sites, two manufacturing sites, and ten alternate groups

\begin{tabular}{ccccc}
\hline & \multicolumn{2}{c}{$\begin{array}{c}\text { Order Satisfaction } \\
\text { Level }\end{array}$} & \multicolumn{2}{c}{$\begin{array}{c}\text { Days of Due Date } \\
\text { Violation }\end{array}$} \\
\hline \multirow{2}{*}{ MIP } & mean & st.dev & mean & st.dev \\
\cline { 2 - 5 } & $\begin{array}{c}92.0 \\
(\mathrm{Opt})\end{array}$ & - & $\begin{array}{c}13.0 \\
(\mathrm{Opt})\end{array}$ & - \\
\hline Proposed & 86.3 & 5.6 & 17.3 & 0.96 \\
\hline $\begin{array}{c}\text { Allocation Confor- } \\
\text { mance for MIP }\end{array}$ & 4.71 & - & 3.92 & - \\
\hline $\begin{array}{c}\text { Allocation Confor- } \\
\text { mance for Proposed }\end{array}$ & 0.65 & 0.17 & 0.65 & 0.17 \\
\hline
\end{tabular}

Table 3. Mean and s.d. ( $\mathrm{n}=50$ for proposed algorithm) of order satisfactory level, days of due date violation, and allocation rate conformance using MIP and proposed algorithm with 10,000 orders, 100 raw material sites, two manufacturing sites, and 20 alternate groups

\begin{tabular}{ccccc}
\hline & \multicolumn{2}{c}{$\begin{array}{c}\text { Order Satisfaction } \\
\text { Level }\end{array}$} & \multicolumn{2}{c}{$\begin{array}{c}\text { Days of Due Date } \\
\text { Violation }\end{array}$} \\
\hline \multirow{2}{*}{ MIP } & mean & st.dev & mean & st.dev \\
\cline { 2 - 5 } & $\begin{array}{c}84.3 \\
\text { (sub-opt) }\end{array}$ & - & $\begin{array}{c}307 \\
\text { (sub-opt) }\end{array}$ & - \\
\hline Proposed & 82.2 & 3.68 & 298 & 16.0 \\
\hline $\begin{array}{c}\text { Allocation Confor- } \\
\text { mance for MIP }\end{array}$ & 95.2 & - & 107.4 & - \\
\hline $\begin{array}{c}\text { Allocation Confor- } \\
\text { mance for Proposed }\end{array}$ & 32.1 & 3.17 & 32.1 & 3.17 \\
\hline
\end{tabular}

rent best sub-optimal solution. In large scale data, proposed model offered the highest-quality solution com- 
pared with MIP (Table 3). In the perspective of order satisfaction level, proposed algorithm shows statistically insignificant difference ( $\mathrm{p}$-value $=.5747$ ).

For further comparison, we run the MIP until it finds the optimal solution. MIP approach found optimal order satisfaction level after 6 hours and 31 minutes with value 86.7 and this result also shows insignificant in statistical view ( $p$-value $=0.2317$ ). For days of due date violation, MIP found the optimal solution after 5 hours and 14 minutes, and the value is 266 days, and the $\mathrm{p}$-value of this result is 0.0533 , but it is still insignificant with significance level $=0.05$. According to this further experiments, we can figure out proposed algorithm is less effective to generate the plan under the condition, which days of due date violation is more important than the order satisfaction level.

\section{DISCUSSION}

We compared the order satisfactory level, days of due date violation and allocation rate violation of three algorithms with three types of data sets.

With the small data set, our proposed model showed almost identical result compared with other two algorithms. Because of the small size of data set, all algorithms could find optimum solution. The proposed algorithm solved the small size planning problem easily.

With the medium data set, the proposed algorithm generated the minimum allocate rate violation solution, and order satisfactory level and days of due date violation were the second best. The mathematical model showed slightly better result, but it consumed much more time than the proposed algorithm. In addition, the proposed algorithm could find the best solution in allocation rate violation criterion.

With the large data set, the proposed algorithm showed the best result on each criterion. The mathematical model failed to find the optimum solution in four hours (4h). The proposed algorithm showed the outstanding days of due date violation and allocation rate violation results while the order satisfactory level of the proposed algorithm showed insignificant difference with that of mathematical model. The proposed algorithm was much powerful when we should use a large data set.

The proposed algorithm was always the fastest algorithm in the experiment; consumed times were always less than ten minutes. This result also supported the usefulness of the proposed algorithm because, in the manufacturing domain, the order changes were very frequent and we should response to the order change quickly; in this situation, using the MIP was not appropriate.

In the view point of allocation rate violation, the proposed algorithm was the most appropriate algorithm for generating well balanced allocation. The balanced allocation could increase sustainability and safety to supply chain by avoiding focused allocation and by preventing unfair allocation.

\section{CONCLUSION}

This study proposed an algorithm to solve optimal allocation alternative selection problems in production scheduling processes; order satisfaction and due date violation were also considered.

The proposed algorithm showed similar level of order satisfactory level and days of due date violation, and allocation rate violation compared to MIP. MIP found the optimum solution, but it failed to find the optimum in work hours (4 hours) with a large date set; the proposed algorithm always generated appropriate production schedules in ten minutes, and the schedule quality of the proposed algorithm was little bit better than that of the mathematical model approach with large data set.

By solving an optimal allocation alternative selection problem with the proposed algorithm, we can allocate appropriate quantities of products and parts to prevent unfair and concentrated allocation which can cause an unstable supply chains. The proposed algorithm was appropriate to large data set and short running time, and will help to generate quick responses to frequent order changes in manufacturing.

\section{ACKNOWLEDGEMENT}

This work was partly supported by the ICT R\&D program of MSIP/IITP (B0101-15-0650, Development of Smart Manufacturing Operation Platform for Hightech Industry).

\section{REFERENCES}

Cachon, G. P. (2003), Supply chain coordination with contracts, Handbooks in Operations Research and Management Science, 11, 229-340.

Chen, Y. Y. (2010), An Analytical Framework for MultiSite Supply Chain Planning Problems, World Academy of Science, Engineering and Technology, 41, 1135-1141.

Ehrgott, M. (2005), Multicriteria optimization, Springer.

Gelders, L. F. and Wassenhove, L. N. V. (1981), Production planning: a review, European Journal of Operational Research, 7(2), 101-110.

Glover, F. (1990), Tabu search: A tutorial, Interfaces, 20(4), 74-94.

Hwang, C. L. and Masud, A. S. M. (1979), Multiple objective decision making-methods and applications: a state-of-the-art survey, Springer, Berlin.

Kibira, Deogratias, et al. (2015), Analysis of Standards Towards Simulation-Based Integrated Production Planning, Advances in Production Management Systems: Innovative Production Management Towards Sustainable Growth, Springer International Pub- 
lishing, 39-48.

Kim, T. et al. (2015), Decomposing Packaged Services Towards Configurable Smart Manufacturing Systems, Advances in Production Management Systems: Innovative Production Management Towards Sustainable Growth, Springer International Publishing, 74-81.

Lin, J. T. and Chen, Y.Y. (2007), A multi-site supply network planning problem considering variable time buckets-A TFT-LCD industry case, The International Journal of Advanced Manufacturing Technology, 33(9), 1031-1044.

Moon, C., Kim, J. and Hur, S. (2002), Integrated process planning and scheduling with minimal total tardiness in multi-plants supply chain, Computers and
Industrial Engineering, 43, 331-349.

Roux, W., Dauzere-Peres, S., and Lasserre, J. B. (1999), Planning and scheduling in a multi-site environment, Production Planning and Control, 10, 19-28.

Timpe, C. H. and Kallrath, J. (2000), Optimal planning in large multi-site production networks, European Journal of Operational Research, 126, 422-435.

Vercellis, C. (1999), Multi-plant production planning in capacitated self-configuring two-stage serial systems, European Journal of Operational Research, 119, 451-460.

Wagner, S. M. and Bode, C. (2006), An empirical investigation into supply chain vulnerability, Journal of Purchasing and Supply Management, 12(6), 301312. 